\title{
Herramientas participativas para el inventario del patrimonio natural y cultural en asentamientos informales. Caso de estudio: barrio El Pozón, UCG6 de la ciudad de Cartagena
}

Participatory Tools for the Inventory of Natural and

Cultural Heritage in Informal Settlements. Case

Study El Pozón, UCG6 from the City Cartagena

Ferramentas participativas para o inventário do patrimônio natural e cultural em assentamentos informais. Estudo de caso do bairro El Pozón, UCG6 da cidade de Cartagena

Alejandra Villamil-Mejía*

Diana María Blanco-Ramírez ${ }^{* \star}$

Recibido: 23 de noviembre de 2020

Aprobado: 29 de julio de 2021

https://doi.org/10.12804/revistas.urosario.edu.co/territorios/a.9952

Para citar este artículo

Villamil-Mejía, A., \& Blanco-Ramírez, D. M. (2022). Herramientas participativas para el inventario del patrimonio natural y cultural en asentamientos informales. Caso de estudio: barrio El Pozón, UCG6 de la ciudad de Cartagena. Territorios, (46), 1-29. https://doi.org/10.12804/revistas.urosario.edu.co/ territorios/a.9952

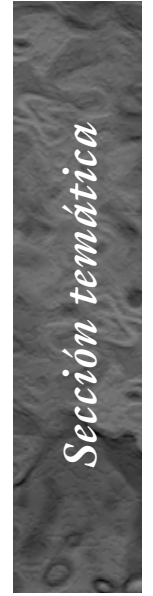

* Profesora asociada, Universidad Jorge Tadeo Lozano. Correo electrónico: claudiaa.villamilm@ utadeo.edu.co. ORCID: bttp://orcid.org/00000003-1682-4445

* Profesora asociada, Universidad Jorge Tadeo Lozano, Seccional del Caribe. Correo electrónico: dianam.blancor@utadeo. edu.co. ORCID: http://orcid.org/0000-0001-55909017 
Palabras clave

Marginalidad urbana; asentamientos informales; patrimonio natural y cultural; herramientas y procesos participativos; El Pozón-

Cartagena.

Keywords Urban marginality; informal settlements; natural and cultural heritage; participatory processes; El PozónCartagena.

Palavras-chave Marginalidade urbana; assentamentos informais; patrimônio natural e cultural; ferramentas e processos participativos; El PozónCartagena.

territarias 46

\section{RESUMEN}

El presente trabajo es un aporte a la identificación de variables e instrumentos de análisis multidimensionales para comprender la transformación morfológica urbana de Cartagena y su región. Se establece un panorama diagnóstico de los efectos del desplazamiento forzado y los cambios en los procesos del crecimiento urbano actuales, que surgen desde la acción de la comunidad para la configuración del territorio en el barrio El Pozón. El diagnóstico se aborda con metodologías cualitativas, apoyadas en métodos etnográficos con enfoque participativo, que dan como resultado, las herramientas que se desarrollan en la fase de diseño lógico y emergente, que decanta la aproximación para la construcción del inventario del patrimonio natural y cultural en asentamientos informales.

\section{ABSTRACT}

The present article contributes to the identification of variables and multidimensional analysis instruments for the understanding of the urban morphological transformation of Cartagena and its region, establishing a diagnostic panorama of the effects of forced displacement and the changes in the current urban growth processes that arise from the action of the community to the configuration of the territory in the El Pozón neighborhood. These diagnoses are approached from qualitative methodologies supported by ethnographic methods with a participatory approach, which result in the tools that are developed in the logical and emergent design phase that opts for the approach for the construction of the inventory of natural and cultural heritage in informal settlements.

\section{RESUMO}

O presente trabalho contribui para a identificação de variáveis e instrumentos de análise multidimensionais para a compreensão da transformação morfológica urbana de Cartagena e sua região, estabelecendo um panorama diagnóstico dos efeitos dos deslocamentos forçados e das mudanças nos atuais processos de crescimento urbano, decorrentes da ação da comunidade para a configuração do território no bairro El Pozón. O diagnóstico é abordado a partir de metodologias qualitativas apoiadas em métodos etnográficos com abordagem participativa, que resultam nas ferramentas que se desenvolvem na fase de design lógico e emergente que opta pela abordagem para a construção do inventário do patrimônio natural e cultural em assentamentos informais. 


\section{Introducción}

La marginalidad urbana en Cartagena y sus implicaciones en la región es una propuesta de investigación de la Escuela de Arquitectura y Hábitat de la Universidad de Bogotá Jorge Tadeo Lozano, que tiene como objetivo construir un diagnóstico multidimensional de los efectos del desplazamiento forzado y sus consecuentes procesos de segregación espacial en la morfología urbana contemporánea del territorio funcional. Para la presente discusión, el aporte significativo se encuentra en la aproximación al inventario del patrimonio realizado con herramientas participativas, que amplían la visión de los límites de lo material e inmaterial y que responden a la pregunta ¿cuáles son los ámbitos que se deben tener en cuenta para la construcción de un diagnóstico del barrio de El Pozón, en la Unidad Comunera de Gobierno No. 6 (UCG6), que permita tomar decisiones en la planificación urbana y formulación de políticas públicas? Y, por otra parte, el diseño participativo, que define las variables de patrimonio natural y cultural, estableciendo así, la prefiguración de un inventario que permita identificar condiciones de habitabilidad, entender la caracterización socioeconómica y los patrones de identidad cultural de las dinámicas urbanas y la asignación de uso del espacio desde el arraigo cultural en los asentamientos informales.
Esto, por supuesto, modifica la metodología del análisis cualitativo en la fase emergente y final del diseño participativo y la configuración de los métodos etnográficos a aplicar en el territorio con su comunidad. Como parte de la estructura para el inventario, las variables establecidas son: el Paisaje cultural, la Medicina Tradicional, el Patrimonio cultural inmaterial asociado a los espacios culturales y los Actos Festivos y lúdicos que se extraen de la Clasificación del Patrimonio Cultural registrados en la Legislación Colombiana (Ley 1185 de 2008) y por las cuales se enmarca — entre otros elementos - el Patrimonio Cultural Inmaterial, PCI.

En adición, esta investigación, se apoya en ejercicios académicos realizados por estudiantes de la Especialización de Diseño Urbano, UTADEO, durante 2019 y 2020 , con el acompañamiento de actores locales como la Fundación Grupo Social-Sede Cartagena y los líderes sociales del Barrio de El Pozón, quienes facilitaron: a) la viabilidad para la realización de entrevistas, talleres de mapeo cartográfico y la observación en campo; y b) la identificación de aquellos espacios y actividades relacionadas, que integran aquellas prácticas $\mathrm{y} / \mathrm{o}$ manifestaciones culturales, haciendo posible que los elementos tangibles e intangibles con valor cultural presentes en el territorio, fueran susceptibles de inventariar. territarios 46

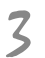




\section{Consideraciones conceptuales y teóricas para el desarrollo del proceso investigativo}

\section{a) Patrimonio natural y cultural (material e inmaterial)}

La Convención de la UNEsCo (1972, p. 1) que busca proteger el patrimonio natural de la evolución de la vida social y económica, entendiendo que su desaparición constituye el empobrecimiento para todos los pueblos del mundo, con valor desde el punto de vista estético o científico. El patrimonio cultural, por su parte, es la herencia de cualquier bien que nuestros antepasados han dejado a lo largo de la historia y que es transmitido de generación en generación, por esto es posible afirmar que el patrimonio cultural es el medio por el cual una comunidad crea vínculos con el territorio que habita, le permite configurar una estructura social, y hace parte de su identidad (MinCultura, 2010, p. 24).

El patrimonio cultural material hace referencia a aquellos bienes muebles o inmuebles que tienen valor desde el punto de vista histórico, artístico, científico, estético, etnológico o antropológico; el patrimonio cultural inmaterial de una comunidad se refleja en sus usos, representaciones, conocimientos, saberes y técnicas, así como en sus espacios culturales. Identificar aquellas actividades colectivas en las que participa un grupo social en particular, y que son dinámicas porque hacen parte de las expresiones de la creatividad y el talento de las colectividades sociales, que tienen un valor simbólico por su valor social y por ser referente de tradición, memoria colectiva e identidad, es importante para garantizar su permanencia en el tiempo y transmisión de generación en generación (MinCultura, 2011a, p. 18).

\section{b) Herramientas participativas y la acción territorial}

En el contexto actual de los procesos de construcción colectiva del territorio, se toman los postulados de Lacol (2018, p. 30) que expone claramente la diferencia entre participación y participacionismo, dejando entrever la importancia de no caer en el segundo, en una atmósfera de optimismo que deja a la primera como una mera herramienta y no como un objetivo en sí mismo. Esto establece una gran diferencia entre los procesos consultivos y los procesos participativos que determinan el rango en el que se cede el poder para crear el espacio y su correspondiente impacto negativo y/o positivo para mitigar conflictos, empoderar y conformar comunidades.

Y por otro lado, la mirada de Paisaje Transversal, que establece una visión de integralidad aplicada a la planificación urbana, considerando de manera transversal las diferentes perspectivas y factores (urbanísticos, sociales, ambientales, económicos, etc.) alineados con los diferentes marcos de ámbito supramunicipal, como 
con las necesidades enunciadas desde la base social y la ciudadanía, introduciendo, perspectivas de cooperación y diálogo entre los diversos agentes en el territorio, aprovechando la participación ciudadana como una "inmejorable fuente de innovación y un canal para enriquecer los proyecto urbanos" (2019, pp. 18-20). Esta consideración, sitúa un escenario de proceso de escucha, entendimiento y actuar conjunto que permite la transformación de la ciudad en coherencia con las dinámicas que se evidencian en el territorio. Ambas posturas, ratifican el momento actual de transición en el que se encuentra el diseño de las políticas, auspiciado por la Agenda 2030 de las Naciones Unidas y los Objetivos de Desarrollo SostenibleODS (Naciones Unidas, 2018).

\section{c) Inventarios para el patrimonio natural y cultural}

A partir del trabajo con los actores sociales del barrio El Pozón (reconociendo la fuerte cohesión social) fue posible determinar por medio de herramientas participativas elementos relacionados con su sentido de bienestar que están ligados al patrimonio natural y cultural. Desde la base de la Ley General de Cultura 1185 de 2008, que reconoce a la cultura como "fundamento de la nacionalidad colombiana", y valorando que el país recientemente ha consolidado programas nacionales y locales que permiten armonizar las necesidades de la comunidad con las convenciones internacionales de la UNESCO - Convención para la Salvaguardia del Patrimonio Cultural Inmaterial (2003) y la política nacional que suscribe esta convención a través de la Ley 1037 de 2006-; se observó el potencial para realizar una aproximación a la construcción de inventarios patrimoniales, reconociéndolos como herramientas útiles para identificar, documentar y hacer visibles los bienes y manifestaciones propias de un lugar o comunidad, partiendo de la base que construir los inventarios de forma participativa contribuye a fortalecer la salvaguardia y gestión de las manifestaciones como establece la Convención y Política de Salvaguardia del Patrimonio Cultural Inmaterial PCI (MinCultura, 2011b, p. 11).

\section{d) Marginalidad Urbana}

\section{Como comenta Llop et al.:}

La - en apariencia permanente-crisis del urbanismo ha constituido el fundamento de los postulados que defienden la desregularización y el libre mercado como elementos básicos para la organización y la ordenación del espacio urbano. A lo largo del tiempo y en especial durante los últimos años, se ha profundizado en la mercantilización del modelo de producción urbana y se han reforzado los procesos de concentración inherente al sistema-de capital, de actividades y de grupos de población de perfil socioeconómico y cultural homogéneo. (2008, p. 13) 
El resultado de este proceso ha sido, no solo la degradación física y funcional de ciertos sectores urbanos, sobre todo en los centros históricos y en las periferias urbanizadas, sino muy particularmente un aumento de los problemas de integración social en las áreas marginadas de la ciudad. Este crecimiento urbano ha tenido un impacto significativo en la estructura de las ciudades latinoamericanas, que hasta ahora se han caracterizado por tener zonas periféricas en crecimiento, aparición de nuevas centralidades en las áreas de expansión, y centros urbanos tradicionales en rápido proceso de deterioro y abandono (Lanzafame \& Quartesan, 2009).

Desde esa mirada, se tienen dos conceptos referentes; el de la Periferia Urbana que recuerda la transformación de la ciudad, en términos cualitativos, en cuanto se desarrolla la construcción de un nuevo espacio entre lo rural y lo urbano (Choay, 1976; Cerasi, 1973) y que hoy en día pierde su base prospectiva, debido a que la situación urbana deja entrever a las periferias como una gran variedad de lugares que reclaman un conocimiento y una intervención adecuada a sus especificidades, por ser lugares inestables y de rápidos cambios de los usos del suelo y del espacio edificado, que absorbe las transformaciones más intensas de la estructura urbana (Arteaga, 2005). Y el concepto de la Marginalidad Urbana, que aparece - de manera inherente- a los descriptitersitarias 46 década de los 90, expone dos escenarios: el de las nociones de "nuevo régimen de marginalidad" o marginalidad avanzada, desarrolladas por Loïc Wacquant (2001), donde el nuevo régimen describe cómo los sectores que antes estaban incluidos en procesos de desarrollo, en los años de consolidación del estado de bienestar, ahora son excluidos. Y el escenario de la revalorización y re-visita, de la vertiente económica-estructural de la marginalidad latinoamericana, representada por $\mathrm{Pa}-$ trick Cingolani (2009) y Agustín Salvia (2010), que concentra tres aspectos: la capacidad explicativa de la noción para escribir fenómenos contemporáneos, la posibilidad que brinda para describir fenómenos heterogéneos y de largo plazo $\mathrm{y}$, finalmente, su utilidad para dar cuenta del problema político de la gestión de los excedentes poblacionales (Delfino, 2012).

\section{Caso de estudio. Barrio El Pozón, UCG6}

El barrio El Pozón está ubicado dentro de la Unidad Comunera de Gobierno N. ${ }^{\circ} 6$ en la zona sur oriental de la ciudad, se caracteriza por ser un asentamiento de origen informal, conformado por campesinos desplazados de la región en los años 60 , en un área considerada zona rural y de expansión con excelentes cualidades para el cultivo del arroz. Hoy en día, limita con el área de protección de la Ciénaga de la Virgen y la vía destapada El Terraplén (norte); la vía de Cordialidad, 
actual acceso terrestre desde y para la ciudad de Barranquilla (sur); el drenaje urbano del caño El Limón (occidente); y la zona de expansión del Distrito (este), abarcando una zona amplia de terrenos bajos e inundables que funcionaban como zona de amortización de la ciénaga y que actualmente concentra una población aproximada de 53.000 habitantes — cifra proyectada del Censo 2005-y una tasa de crecimiento de $3,9 \%$ al año, que consolida el $5 \%$ de la población total de Cartagena y el $60 \%$ de la población total de la UCG6.
En estas condiciones de densidad, el territorio presenta una ocupación y acceso a la propiedad, no necesariamente atado al terreno en sí, sino que permite diferentes formas de habitar que vinculan la productividad económica, estableciendo un símbolo de estatus social, dependiendo del área de la parcelación.

Como se observa en la figura 1, esta estructura económica, relacionada con la propiedad y la productividad, se evidencia en el dinamismo comercial y su diversidad de escenarios, siendo estos, la vivienda, los establecimientos comerciales

Figura 1. Actividad económica en hogares y emprendimiento, Barrio El Pozón

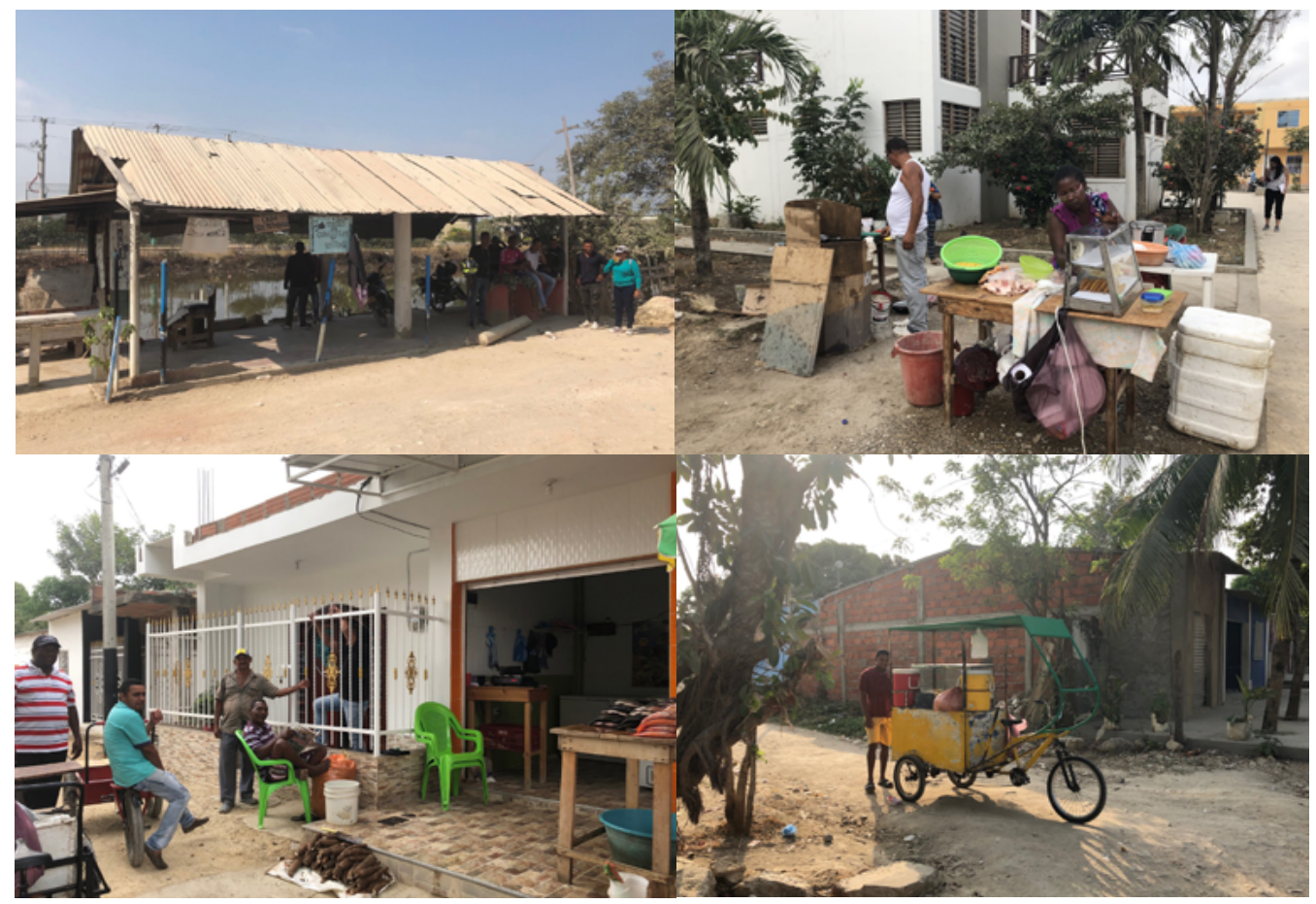

Fuente: estudiantes del Taller Electivo disciplinar Desarrollo Social, febrero, 2019. 
no regularizados, el espacio público, los puestos ambulantes informales y los servicios domiciliarios. Estas actividades demuestran una alta vitalidad y autonomía del sector, que fortalecen la economía de escala compuesta por un $85 \%$ de hogares con ingreso a través de emprendimiento, $24 \%$ hogares con negocio propio o independiente, $15 \%$ hogares con negocios que tienen matrícula mercantil, $14 \%$ hogares con negocio propio que tienen RUT, y $4 \%$ hogares con negocios que declaran renta y un $32 \%$ de hogares con negocio propio que tienen empleados con aportes a la seguridad social (Econometría Consultores, 2014). Esta dinámica se refleja en el espacio (figura 2), registrando una alta ocupación definida por los corredores de obtención, transformación y distribución de productos, entre el borde de ciénaga y la vía de la Cordialidad para los barrios de Fredonia y Olaya Herrera; y que, en el caso del barrio El Pozón los polariza hacia el borde del intercambiador vial y la reciente conexión y apertura de la troncal de Aguas del Caribe.

Esta condición morfológica, dada por la vías principales perimetrales y la presencia de la ciénaga, representa un papel prioritario en el ordenamiento territorial de Cartagena, que tiene como desafíos responder al aumento de la pobreza y de las necesidades básicas insatisfechas, temas estrechamente ligados al deterioro del entorno ambiental y al riesgo por inundación; así mismo, el crecimiento poblacional actual aumenta la demanda de tierras urbanizables, descuida la inclusión social e incrementa la falta de oportunidades del mercado laboral (PNUMA, 2009). Esto deja al barrio en una situación dependiente de las decisiones de la política pública para la transformación que requiere el soporte de las infraestructuras funcionales de la ciudad para su desarrollo y la incorporación de las dinámicas locales de la UCG6 en esa planeación (figura 2).

Teniendo en cuenta los retos urbanos de la Agenda de Sostenibilidad 2030 (Naciones Unidas, 2018) y la nueva supraagenda, que busca alinear los esfuerzos individuales para que aporten al progreso social, económico y medioambiental, se tiene: 1. Pobreza, informalidad y desigualdad, problema presente con una tasa de informalidad por encima del $42 \% ; 2$. Educación de calidad, que logró un mejor acceso en términos de cobertura, pero no en cuanto a la calidad; 3. Cambio climático y resiliencia urbana, con tarea para disminuir los riesgos — por inundaciónsobre entornos urbanos; 4. Sostenibilidad e inclusión, que dentro de sus elementos mide la calidad del espacio público, como espacio para la incursión; y en temas de sostenibilidad, el manejo integral de aguas residuales y la vulnerabilidad por el desabastecimiento del recurso hídrico, las tres de relevancia para el caso de estudio; 5. Seguridad, paz y convivencia, que presenta como desafío la seguridad ciudadana y la coexistencia pacífica, ambas exigen un trabajo para disminuir la intolerancia y una oportunidad para vincular 
Figura 2. Desarrollo de las actividades económicas de la UCG6
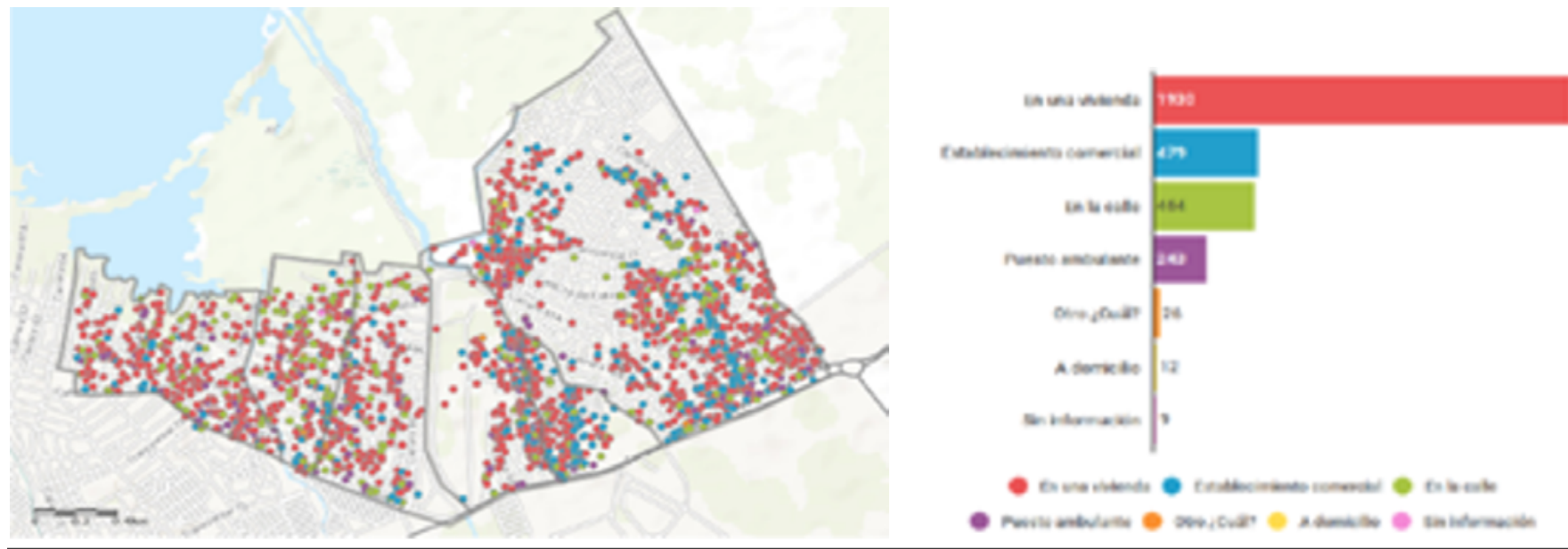

Fuente: Estudio Brandstrat 2017, Línea estratégica económica de Cartagena. Área de Investigación, Planeación, Seguimiento y Evaluación, Vicepresidencia de Desarrollo y Fundación Grupo Social.

procesos de postconflicto con desarrollo sostenible, cuidando así el problema de desplazamiento, que se debe atender en el caso de estudio. Los puntos anteriormente mencionados han sido establecidos a partir de los resultados de la primera medición de los Objetivos de Desarrollo Sostenibles.

Los estudios e iniciativas que se adelantan en las áreas colindantes a las Ciénaga de la Virgen en Cartagena por parte del Gobierno, a través de la alcaldía y el Observatorio Ambiental de Cartagena, el Instituto Alexander Von Humboldt (IAvH, 2016) y el Instituto de Investigaciones Marinos y Costeras (INVEMAR et al., 2012), los proyectos liderados por organismos sin ánimo de lucro como Fundación Social y Fundación Ecoprogreso; y otros como la Agencia de Cooperación Internacional Alemana (GIZ) con el Banco Interamericano de Desarrollo (BID), reconocen el establecimiento claro de las líneas de acción en temas ambientales y sociales, en los que se requiere un estudio de reconocimiento del lugar físicoespacial para consolidar las acciones que permitan mejorar la calidad de vida de los habitantes asentados alrededor de la ciénaga (figura 3 ). Y que, en términos territoriales, solventen la falta de conexión entre todas las iniciativas y la definición de un plan de ordenamiento territorial actualizado, con acciones individuales de impacto escalar y determinando el desarrollo futuro bajo el diseño de herramientas para la implementación de procesos participativos en el diseño de ciudad. tersitarios 46 


\section{Figura 3. Conectividad terrestre y fluvial entre El Pozón y Cartagena}

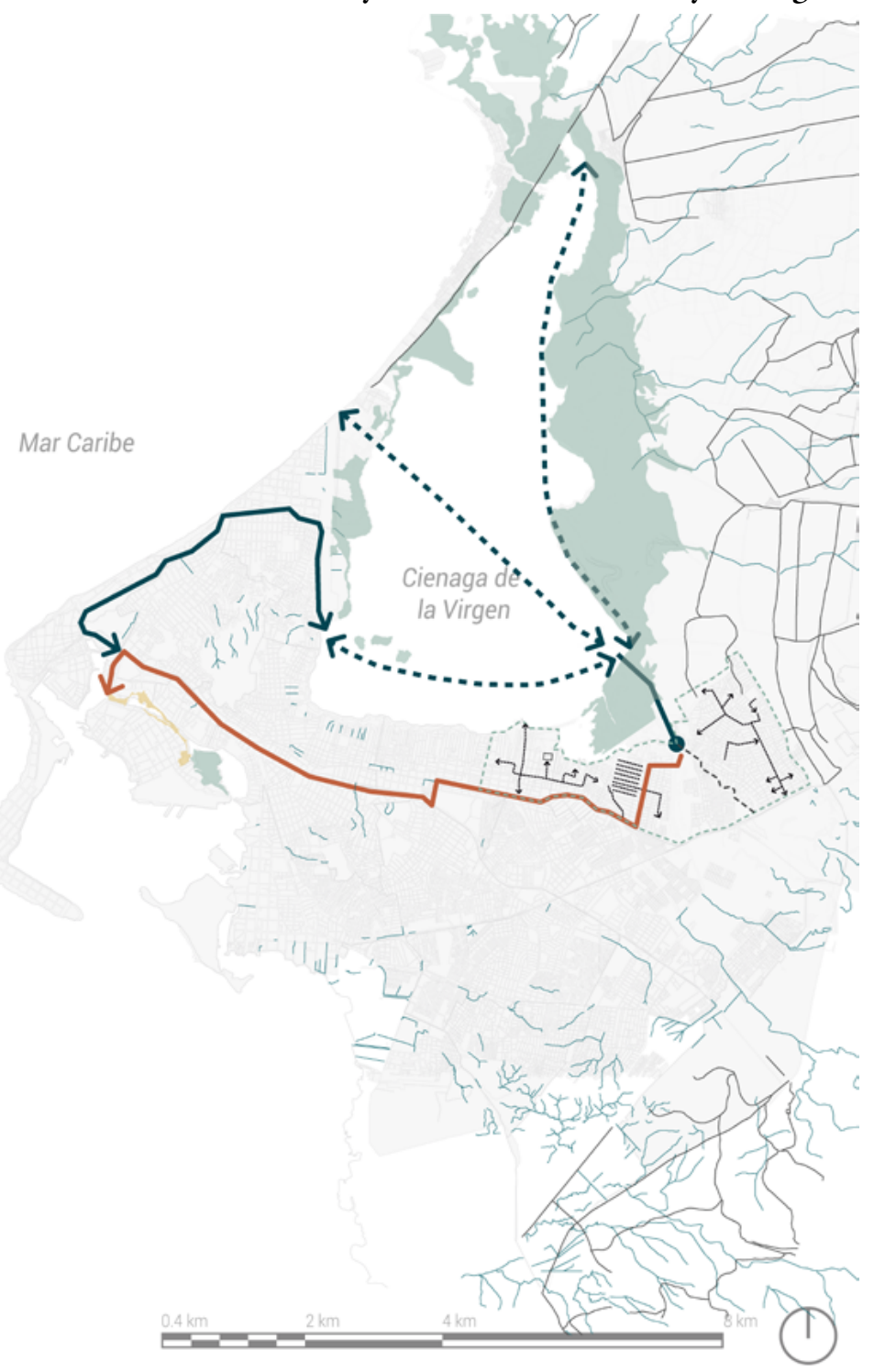

territarias 46

$\begin{array}{lll}\text { Manglares } & \square \text { Propuestas } & \text {-.- Conexión fluvial por ciénaga } \\ \text { Manglar manejo } & - \text { Conexión terrestre } & - \text { Conexión fluvial por canales } \\ \text { Arroyos } & \text {-.- Conexiones } & - \text { Vias }\end{array}$

Fuente: Elaborado por Nicolás Quintero asistente de investigación UJTL, junio, 2020. 


\section{Metodología y proceso participativo}

La investigación es cualitativa de tipo explicativo, en cuanto se orienta a establecer relaciones de asociación entre las variables, bajo la figura de estudio de caso. Esta se caracteriza, por su aproximación empírica, que condiciona la recolección de datos para la comprensión de los fenómenos urbanos de la marginalidad, desde la relación observacional en la unidad de análisis espacial del barrio El Pozón en la UCG6.
El Diseño de la investigación propone las siguientes Categorías Urbanas para el estudio.

Para la tabla 1 se establecieron los siguientes criterios de relevancia: a) Una perspectiva multiescalar, que cubre las dinámicas de la ciudad, la unidad comunera de gobierno, el barrio y su espacio público/privado, a través de métodos etnográficos que abordan las categorías urbanas sus variables; b) Una aproximación a los asentamientos informales y su relación con el patrimonio cultural; c) Destacar los hallazgos principales que

Tabla 1. Diseño de investigación. Establecimiento de Categorías Urbanas

\begin{tabular}{|l|l|}
\hline Categorías Urbanas & \multicolumn{1}{|c|}{ Descripción } \\
\hline Sistema Construido & $\begin{array}{l}\text { El sistema construido, definido por la morfología urbana, trama urbana y tipologías } \\
\text { edificatorias en su calificación regular, irregular y formas especiales como las exentas } \\
\text { y cul-de-sac que prefiguran las formas de ocupación. }\end{array}$ \\
\hline $\begin{array}{l}\text { Sistema de } \\
\text { espacio público y } \\
\text { equipamientos }\end{array}$ & $\begin{array}{l}\text { El sistema de espacio público y equipamentos, soportado por la clasificación de servi- } \\
\text { cios urbanos básicos y unidades colectivas de salud, educación, seguridad ciudadana } \\
\text { y bienestar social que decantan la red de apoyo y atención para la población. }\end{array}$ \\
\hline $\begin{array}{l}\text { Sistema de } \\
\text { movilidad, } \\
\text { conectividad y } \\
\text { accesibilidad }\end{array}$ & $\begin{array}{l}\text { El sistema de movilidad, conectividad y accesibilidad; reflejado por el trazado de líneas } \\
\text { de transporte púbico motorizado formal e informal de los mototaxis y bicitaxis y las } \\
\text { puntos de paraderos que espontáneamente se consolidan en el barrio. Así como, los } \\
\text { ejes centrales que centran los flujos peatonales. }\end{array}$ \\
\hline Sistema Natural & $\begin{array}{l}\text { El sistema natural, cubierto por la estructura ecológica principal y sus áreas verdes } \\
\text { recreativas menores a 2 Ha, áreas verdes destacadas, áreas productoras con función } \\
\text { amortiguadora, áreas forestales y zonas ambientales y de conservación natural. Reco- } \\
\text { noce también, el sistema de drenaje urbano entre los caños de escorrentías de agua, } \\
\text { canales hídricos urbanos y las zonas de operación de dragado y los riesgos ambientales } \\
\text { por inundación que se derivan de estos ya sea por amortiguación del área ambiental } \\
\text { o por contaminación derivadas del depósito de basuras. }\end{array}$ \\
\hline $\begin{array}{l}\text { Sistema socioeconó- } \\
\text { mico y sociocultural }\end{array}$ & $\begin{array}{l}\text { El sistema socioeconómico y sociocultural, reflejado por la actividad comercial formal } \\
\text { e informal y los espacios de encuentro que se asocian a estos. }\end{array}$ \\
\hline
\end{tabular}

Fuente: elaboración propia. Mayo, 2019. 
se evidencian entre el espacio físico y las dinámicas socio-culturales, para aportar a la toma de decisiones en la planificación del territorio, que pone en valor el paisaje natural y cultural del lugar; d) La no declaración de conceptos previos acerca de patrimonio cultural durante el proceso del diseño participativo para identificar la fortaleza de las manifestaciones y elementos urbanos en función del reconocimiento colectivo, reflejando el valor simbólico de las situaciones registradas en el caso de estudio.

Como valor de flexibilidad en la capacidad para comprender una o varias situaciones en campo y aprovechar las ocasiones imprevistas, que ajustan el "proceso cognitivo y una simple validación e ideas ya formuladas" (Bailyn 1977, en Marradi et al., 2018), la investigación se precisa, diseña y planifica desde las actividades de investigación (tabla 2) y el continuum que se arma en tres momentos: Fase Lógica, Emergente y Final, que reconocen las decisiones mínimas a las cuales se somete el método empírico.

Con las actividades de planeación y evitando la multiplicidad de métodos e interpretación de ellos, que dejan una escasa visión del conjunto, la investigación se ajusta en función de los resultados de construcción colectiva en los parámetros de diseño (Salgado, 2007); al tiempo que se enriquece con la recolección y análisis de datos, los cuales incrementan la aplicación de criterios convencionales, valoran la adecuación y calidad de la investigación (Sandín Esteban, 2000). Los procedimientos utilizados parten de la triangulación de datos, conceptos teóricos y métodos; y la validación de información desde los participantes y el establecimiento de patrones (Johnson, 1997) (tabla 3).

Con el propósito de aportar elementos de análisis y propuestas que orienten los procesos de planeación en asentamientos informales (tabla 4), se utilizan métodos cualitativos de investigación enmarcados en procesos participativos. Estos métodos permiten manejar información de la población local involucrada, obtener información específica de los valores, opiniones, contexto social y población particular, con lo cual se producen hallazgos que eliminan intermediarios en la obtención de la información y se logra colectivizar el valor del patrimonio desde el reconocimiento de las prácticas sociales que se llevan a cabo en el lugar; asimismo, la valoración de los saberes que se pueden asociar al reconocimiento de las prácticas. Identificar los valores materiales e inmateriales presentes, que permiten reconocer dinámicas de cohesión social y que denotan un alto sentido de organización y empoderamiento, da cuenta de una visión clara del aprovechamiento del territorio muy a pesar de sus condiciones de marginalidad.

Dentro de las medidas de fiabilidad y validez del estudio, emerge la incorporación de tres variables para el análisis, que resultaron de la discusión grupal sobre las dinámicas urbanas identificadas en el caso 
Tabla 2. Diseño de actividades de investigación

\begin{tabular}{|c|c|}
\hline Actividades de investigación & Insumos finales \\
\hline $\begin{array}{l}\text { Análisis y caracterización de los procesos históricos de expansión y poblamiento } \\
\text { del caso de estudio a escala de la región con ayuda de herramientas de sistemas } \\
\text { de información geográfica SIG }\end{array}$ & $\begin{array}{l}\text { Documento previo de con- } \\
\text { texto }\end{array}$ \\
\hline $\begin{array}{l}\text { Caraterización de las dimensiones y variables de análisis a la luz de las dinámicas } \\
\text { observadas en el caso de estudio }\end{array}$ & Datos de análisis \\
\hline $\begin{array}{l}\text { Definición de linemientos generales y criterios para la recolección y el análisis } \\
\text { de la información }\end{array}$ & $\begin{array}{l}\text { Fichas de restro e índices de } \\
\text { cartografias }\end{array}$ \\
\hline $\begin{array}{l}\text { Salida de campo 01. Recolección de la información } 2019 \text {-S1. Estudiantes de } \\
\text { taller de proyecto de arte y ciudad y taller electivo disciplinar desarrollo social } \\
\text { del programa de arquitectura de la escuela de arquitectura y hábitat de la UJTL } \\
\text { y fundación Grupo Social - Sede Cartagena }\end{array}$ & $\begin{array}{l}\text { Observación en campo, } \\
\text { resgistro fotográfico y en- } \\
\text { trevistas semiestructuradas }\end{array}$ \\
\hline Selección, clasificación y análisis de la información recogida en campo & $\begin{array}{l}\text { Info base para talleres par- } \\
\text { ticipativos }\end{array}$ \\
\hline $\begin{array}{l}\text { Salida de campo } 02 \text {. Taller comparativo de datos entre observación de } \\
\text { campos de estudiantes y conicimiento local de comunidad 2019-S2. Estu- } \\
\text { diantes de taller de proyecto de arquitectura y ciudad y taller electivo disciplinar } \\
\text { Desarrollo Social del programa de Arquitectura de la escuela de Arquitectura } \\
\text { y habitat de la UJTL, Fundación Grupo Social - Sede Cartagena y comunidad }\end{array}$ & $\begin{array}{l}\text { Mapeo cartográfico com- } \\
\text { parado con actores }\end{array}$ \\
\hline $\begin{array}{l}\text { Reclasificación de información, ajuste del análsis preliminar y aproximación al } \\
\text { estado diagnóstico }\end{array}$ & $\begin{array}{l}\text { Cartográfias por sistemas y } \\
\text { ajustes de variables y datos }\end{array}$ \\
\hline $\begin{array}{l}\text { Salida de campo } 03 \text {. Recorrido urbano de reconocimiento local dirigido por } \\
\text { lideres de la comunidad 2019-S2. Estudiantes de Especialización de Diseño } \\
\text { Urbano de la Escuela de Arquitectura y hábitat de la UJTL, Fundación Grupo } \\
\text { Social - Cartagena y lideres sociales, ambientales y culturales }\end{array}$ & Recorridos urbanos \\
\hline $\begin{array}{l}\text { Reclasificación de información, ajustes del análisis preliminar y aproximación } \\
\text { al estado diagnóstico }\end{array}$ & Cartográfias por sistemas \\
\hline $\begin{array}{l}\text { Salida de campo } 04 \text {. Taller de validación } 2020 \text {-S1. Estudiantes de Especia- } \\
\text { lización de diseño Urbano de la Escuela de Arquitectura y hábitat de la UJTL, } \\
\text { Fundación Grupo Social - Sede Cartagena y lideres sociales, ambientales y } \\
\text { culturales }\end{array}$ & $\begin{array}{l}\text { Mapeo cartográfico de vali- } \\
\text { dación y grupo focal }\end{array}$ \\
\hline $\begin{array}{l}\text { Elaboración de una síntesis con los principales hallazgos y definición de unas } \\
\text { líneas de actuación que sustenten la definición de una política pública }\end{array}$ & Documento final \\
\hline
\end{tabular}

Fuente: elaboración propia. Mayo, 2019. 
Tabla 3. Diseño de investigación y su Continuum

\begin{tabular}{|c|c|c|c|}
\hline & Fase lógica & Fase Emergente & Fase final \\
\hline $\begin{array}{l}\text { Defeni- } \\
\text { ción del } \\
\text { problema }\end{array}$ & $\begin{array}{l}\text { Buscar tema explorando datos } \\
\text { en todos los modos posibles }\end{array}$ & $\begin{array}{l}\text { Compilación análisis de to- } \\
\text { dos los datos que se refieren a } \\
\text { temas, ideas, conceptos, inter- } \\
\text { pretación y proposiciones }\end{array}$ & $\begin{array}{l}\text { Interpretación de datos en el } \\
\text { contexto en el que fueron re- } \\
\text { cogidos }\end{array}$ \\
\hline $\begin{array}{l}\text { Diseño del } \\
\text { trabajo }\end{array}$ & $\begin{array}{l}\text { Revisión de material biblio- } \\
\text { gráfico, seguir la pista de te- } \\
\text { mas, interpretaciones ideas, } \\
\text { buscar temas emergentes y } \\
\text { elaborar categorías de análisis }\end{array}$ & $\begin{array}{l}\text { Desarrollo de categorías de co- } \\
\text { dificación, clasificación de da- } \\
\text { tos, examinar y refinar analizar }\end{array}$ & $\begin{array}{l}\text { Datos solicitado o no solicita- } \\
\text { dos, diferencias entre lo que } \\
\text { dice la gente cuando esta dola } \\
\text { o en grupo, diferenciar entre la } \\
\text { perspectiva de una sola persona } \\
\text { y las de un grupo más amplio }\end{array}$ \\
\hline $\begin{array}{l}\text { Recogida } \\
\text { de datos }\end{array}$ & $\begin{array}{l}\text { Categorías urbana: sistema } \\
\text { construido, sistema de espa- } \\
\text { cio público y equipamiento, } \\
\text { sistema natural y sistema de } \\
\text { movilidad, sistema natural y } \\
\text { sistema socio-económico }\end{array}$ & $\begin{array}{l}\text { Sub-categorías urbana: espa- } \\
\text { cios de encuentro, barreras } \\
\text { invisibles, accesibilidad a te- } \\
\text { rritorio multiescalar, riesgos } \\
\text { ambientales y drenaje urbano }\end{array}$ & $\begin{array}{l}\text { Anexo a sub-categorías: Paisje } \\
\text { cultura, Medicina tradicional, } \\
\text { patrimonio cultural inmaterial } \\
\text { asociado a los espacios cultu- } \\
\text { rales y actos festivos y lúdicos }\end{array}$ \\
\hline $\begin{array}{l}\text { Análisis } \\
\text { de datos }\end{array}$ & $\begin{array}{l}\text { Análisis descriptivo univaria- } \\
\text { ble }\end{array}$ & $\begin{array}{l}\text { Análisis comparado (fuente de } \\
\text { información) }\end{array}$ & Análisis correlacional \\
\hline $\begin{array}{l}\text { Validación } \\
\text { e informe }\end{array}$ & $\begin{array}{l}\text { Criterios de validación conven- } \\
\text { cional (Validez interna, validez } \\
\text { externa) }\end{array}$ & $\begin{array}{l}\text { Criterios de validación conven- } \\
\text { cional (Validez interna, validez } \\
\text { exerna, fiabilidad) }\end{array}$ & $\begin{array}{l}\text { Criterios de validación conven- } \\
\text { cional (Validez interna, validez } \\
\text { externa, fiabilidad y objetivi- } \\
\text { dad) }\end{array}$ \\
\hline
\end{tabular}

Nota: Sígase el enfoque de análisis en progreso en investigación cualitativa basado en tres momento: descubrimiento, codificación y relativización de datos de Taylor y Bogdan (1990).

Fuente: elaboración propia. Mayo, 2019.

Tabla 4. Herramientas y técnicas aplicadas al proceso participativo

\section{territarias 46}

\begin{tabular}{|l|l|c|}
\hline $\begin{array}{c}\text { Método } \\
\text { Etnográfico }\end{array}$ & \multicolumn{1}{|c|}{ Objetivo } & Resultado Esperado \\
\hline $\begin{array}{l}\text { Observación } \\
\text { de campo }\end{array}$ & $\begin{array}{l}\text { Establecer algún tipo de conocimiento empí- } \\
\text { rico con los objetos/sujetos/situaciones a los } \\
\text { fines de descripción, explicación o compresión }\end{array}$ & Categorías y variables de la unidad de análisis \\
\hline $\begin{array}{l}\text { Levantamien- } \\
\text { to Urbanos }\end{array}$ & $\begin{array}{l}\text { Representar espacio real con las condicionales } \\
\text { que reflejan la simplicidad de las estructuras } \\
\text { y codificaciones }\end{array}$ & $\begin{array}{l}\text { Cartografía de estado actual y elementos } \\
\text { singulares del territorio }\end{array}$ \\
\hline
\end{tabular}




\begin{tabular}{|l|l|l|}
\hline \multicolumn{1}{|c|}{$\begin{array}{c}\text { Método } \\
\text { Etnográfico }\end{array}$} & \multicolumn{1}{|c|}{ Objetivo } & \multicolumn{1}{c|}{ Resultado Esperado } \\
\hline $\begin{array}{l}\text { Registro } \\
\text { Fotográfico }\end{array}$ & $\begin{array}{l}\text { Crear muros colaborativos para la represen- } \\
\text { tación del territorio }\end{array}$ & $\begin{array}{l}\text { Fotografías que denoten la apropiación del } \\
\text { espacio a través de la actividad y el paisaje } \\
\text { urbano en si mismo }\end{array}$ \\
\hline $\begin{array}{l}\text { Mapeo } \\
\text { Cartográfico }\end{array}$ & $\begin{array}{l}\text { Obtener información gráfica localizada que } \\
\text { señalen la ocupación en el territorio como } \\
\text { representaciones naturales e incuestionables }\end{array}$ & $\begin{array}{l}\text { Cartografías de síntesis que se permitan cons- } \\
\text { truir la imagen colectiva del territorio en sus } \\
\text { proyecciones y limites del mapeo }\end{array}$ \\
\hline $\begin{array}{l}\text { Entrevista } \\
\text { Semiestruc- } \\
\text { turada }\end{array}$ & $\begin{array}{l}\text { Obtener información sobre las experiencias } \\
\text { de las personas que habilitan en los entornos } \\
\text { estudiados }\end{array}$ & $\begin{array}{l}\text { Percepciones colectivos que se reconocen } \\
\text { dentro de los sistemas urbanos y el registro } \\
\text { de situaciones cotidianas o extraordinarias } \\
\text { que se asocian al espacio }\end{array}$ \\
\hline $\begin{array}{l}\text { Recorrido } \\
\text { Urbano }\end{array}$ & $\begin{array}{l}\text { Discutir sobre el terreno y convertir una ac- } \\
\text { tividad pasivaen un acto más del proceso de } \\
\text { participación, a partir de las explicaciones de } \\
\text { quien guía el grupo }\end{array}$ & $\begin{array}{l}\text { Factores colectivos que se reconocen den- } \\
\text { tro de los sistemas urbanos y el registro de } \\
\text { situaciones cotidianas o extraordinarias que } \\
\text { se asocian al espacio }\end{array}$ \\
\hline
\end{tabular}

Fuente: elaboración propia. Mayo, 2019.

de estudio del barrio El Pozón (figura 4); y que, tal como establece el Ministerio de Cultura (MinCultura, 201la), aparecieron como manifestaciones del Patrimonio Cultural inmaterial, siendo estas: el paisaje cultural, la medicina tradicional, el patrimonio cultural asociado a los espacios culturales de encuentro, y los actos festivos y lúdicos. Como se muestra en la tabla 5, se caracterizan así:

Figura 4. Actividades de métodos etnográficos en campo - Observación de campo y entrevista semiestructurada, barrio El Pozón
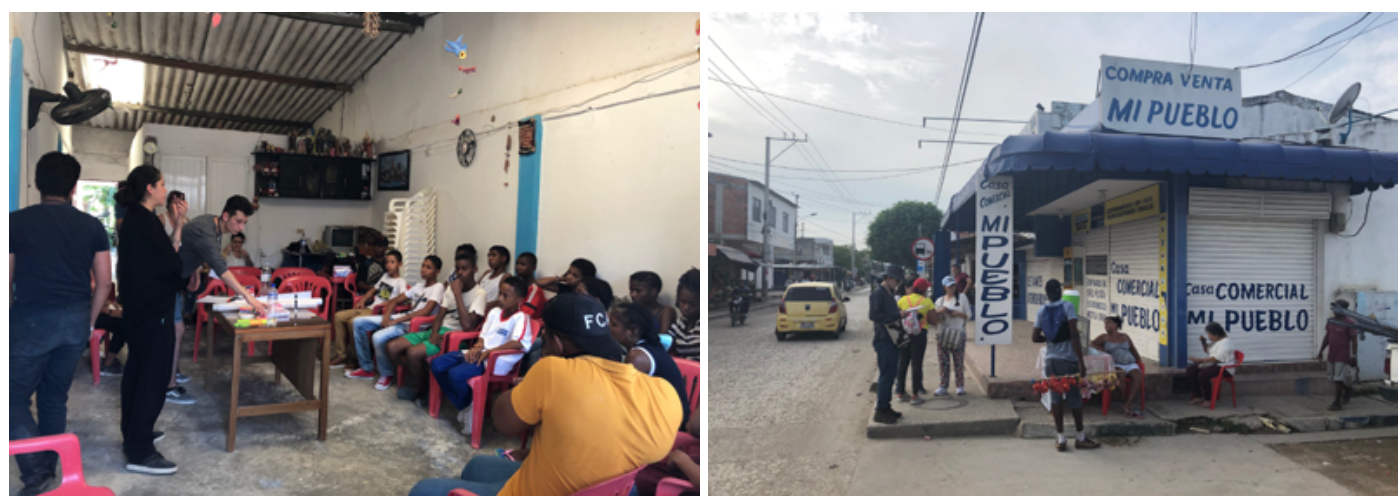

Fuente: estudiantes Taller Electivo disciplina Desarrollo Social 2019-S1. Febrero, 2019. 
Tabla 5. Variables de la unidad de análisis

\begin{tabular}{|l|l|}
\hline Variables de análisis & \multicolumn{1}{c|}{ Descripción } \\
\hline Paisaje cultural & $\begin{array}{l}\text { El paisaje cultural es una categoría propuesta por la UnESCo en 1992, que reúne el } \\
\text { paisaje natural, material e inmaterial y da cuenta de cómo una comunidad presente } \\
\text { en un territorio natural lo modifica para poder vivir allí, dando cuenta de los pro- } \\
\text { cesos ambientales, culturales y sociales a lo largo del tiempo. En el paisaje cultural } \\
\text { se tienen en cuenta elementos como el paisaje, las formas de vida, las políticas y los } \\
\text { bienes muebles e imuebles que hacen parte de la identidad y que permiten recono- } \\
\text { cer un valor ambiental, cultural, simbólico, entre otros, teniendo en cuenta, las } \\
\text { actuaciones que se realizan sobre ese territorio puesto que pueden comprometer su } \\
\text { futuro y permanencia en el tiempo, teniendo en cuenta que es dinámico y sensible } \\
\text { a los cambios culturales, sociales, económicos y físicos }\end{array}$ \\
\hline Medicina Tradicional & $\begin{array}{l}\text { La medicina tradicional es un campo del pCI relacionada con conocimientos y } \\
\text { prácticas tradicionales para la prevención y tratamiento de enfermedades, así como } \\
\text { los conocimientos botánicos asociados como el manejo de plantas con fines medi- } \\
\text { cinales (herbolario medicinal) }\end{array}$ \\
\hline $\begin{array}{l}\text { Patrimonio cultural in- } \\
\text { material asociado a los } \\
\text { espacios culturales }\end{array}$ & $\begin{array}{l}\text { El patrimonio cultural inmaterial asociado a los espacios culturales es donde po- } \\
\text { demos encontrar el ensamble de tres tipos de patrimonio: el intangible, el material } \\
\text { y el natural, espacios con un fuerte significado espiritual o histórico relacionados } \\
\text { como sitios urbanos de alto valor funcional que son referentes culturales o hitos } \\
\text { de la memoria ciudadana }\end{array}$ \\
\hline Actos festivos y lúdicos \\
\hline $\begin{array}{l}\text { Los actos festivos y lúdicos son aquellos acontecimientos sociales y culturales que se } \\
\text { realizan periódicamente con fines lúdicos, generadores de identidad, permanencia } \\
\text { y cohesión social }\end{array}$ \\
\hline
\end{tabular}

Fuente: elaboración propia. Febrero, 2020.

Investigaciones relacionadas con el abordaje del patrimonio, como Olimpia Niglio (2014) y Liliana Fracasso y Sandra Mesa (2019) con la red de Lo Patrimoniable, que de una u otra forma establecen el control de credibilidad para el planteamiento hipótesis, se incluyen las manifestaciones culturales-populares que se alojan en asentamientos informales y marginales haciendo parte de su identidad cultural como parte constructo de la clasificación del patrimonio.

\section{Discusión y hallazgos. Aporte a la aproximación del inventario del patrimonio cultural}

A partir de la aplicación de herramientas participativas en El Pozón se identificaron manifestaciones culturales que hacen parte de la identidad de los habitantes del barrio, se introdujeron las variables de análisis mencionadas, que se extraen de la Clasificación del Patrimonio Cultural registrado en la Legislación Colombiana. En los talleres de mapeo cartográfico se 
reveló el conocimiento existente sobre conceptos relacionados con patrimonio natural y cultural valorados como riqueza y manifestaciones culturales emergentes, que hacen parte del patrimonio del barrio como: grupos de danza, huertas urbanas y patios productivos (figura 5).

\section{Hallazgo 1. El valor del Paisaje Cultural como riqueza ambiental}

La variable de identificación Paisaje Cultural reconoce el valor de la Ciénaga de la Virgen como Patrimonio Natural de la ciudad y el valor ambiental del espacio público como servicio ecosistémico para la construcción de la cartografía que facilita rescatar y caracterizar elementos específicos para la estructura ecológica principal de El Pozón. La EEP se clasificó en áreas verdes recreativas menores a dos ha., áreas productoras y protectoras, áreas con funciones amortiguadoras, áreas forestales, áreas verdes, las zonas ambientales de ciénaga y dos patios interiores que cuentan con algunos árboles centenarios que los habitantes identifican como preexistencias con gran valor.

Como se presenta en la figura 6 , las áreas verdes recreativas, menores a dos ha, se relacionan con espacios libres asociados a equipamientos dotacionales, algunos de estos con actividades culturales y deportivas como las fiestas patronales, el reinado popular y los campeonatos de microfútbol. Con el ejercicio participativo se identificó el valor de estos espacios públicos auto gestionados como áreas productivas para el cultivo de plantas medicinales como el orégano, la sábila, el limoncillo; frutales como mango, níspero, guayaba, guanábana y tamarindo; y una zona de maderables que se utiliza para la construcción de muebles. Los centros

Figura 5. Actividades de métodos etnográficos en campo. Recorrido urbano y mapeo cartográfico, barrio El Pozón

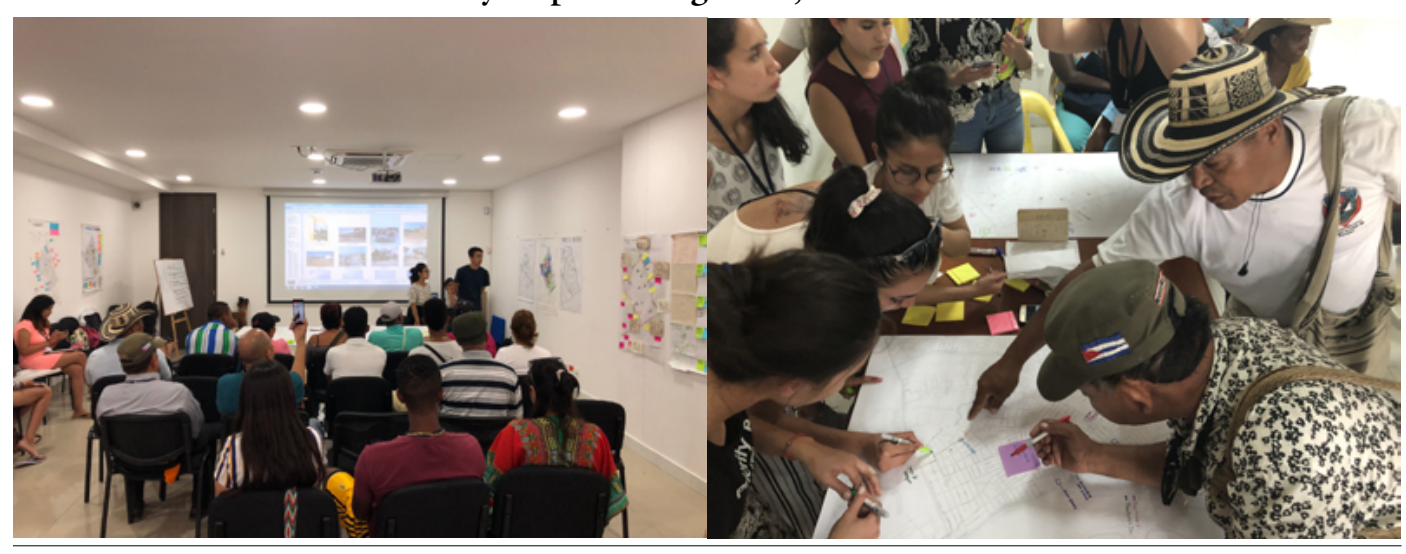

Fuente: estudiantes Taller Electivo disciplina Desarrollo Social 2019-S1. Febrero, 2019. 
Figura 6. Sistema Natural. Estructura Ecológica Principal. Cartografía de síntesis, basada en las cartografías participativas

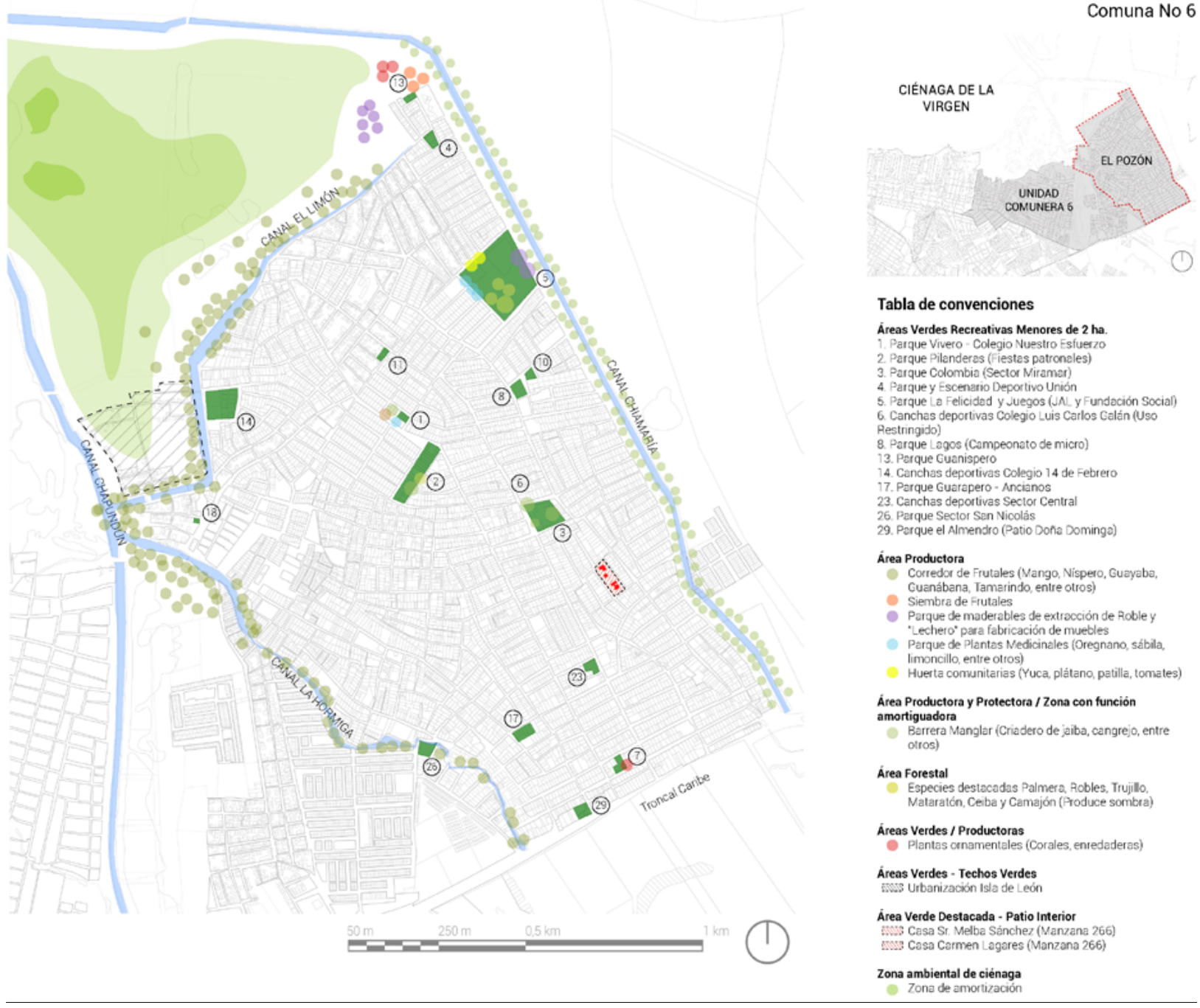

Fuente: Elaborado por Nicolás Quintero asistente de investigación UJTL. Junio, 2020.

de manzana se consideran como oportunidad de productividad para huertas

tersitarios 46 urbanas donde se cultiva yuca, plátano, patilla y tomate; las mismas personas del barrio y los dueños de los predios que participan en estos espacios, se encargan de la seguridad y el manejo de mantenimiento a mediano y largo plazo, además 
de recibir el beneficio de los insumos alimenticios.

En las áreas forestales se registran palmeras, robles, trujillo, matarratón, ceibas y camajones que cumplen la función de dar sombra y contribuir a disminuir el efecto de isla de calor. Las áreas con función amortiguadora cuentan con manglares como barrera protectora ante las inundaciones y sirven como fuente de alimento y generación de recursos económicos puesto que se localizan criaderos de jaiba y camarón.

Desde la base del patrimonio natural se toman las áreas que son el hábitat de especies animales y vegetales amenazadas. En este caso, se considera que la Ciénaga de la Virgen tiene el mayor valor de esta región del país, siendo una laguna costera, la segunda ciénaga de Colombia y un humedal marino-costero conectado con el mar, que hace parte de las cuencas hidrográficas prioritarias de ordenamiento y planificación en la región (IAvH, 2016, pp. 8-9). La ciénaga es una fuente de recursos pesqueros para los actores que viven en su borde y para los asentamientos marginales sobre la vía perimetral. Sin embargo, se han generado conflictos socio-ecológicos de conexión fluvial con el resto de la ciudad a través del caño de Juan Angola y canales pequeños con la laguna del Cabrero, que a su vez se conecta con las lagunas de Chambacú y San Lázaro para dar con el caño de Bazurto, todos con altas afectaciones a manglares y alta contaminación del agua por agentes externos.
En términos de gestión ambiental y política pública, las entidades de la administración pública y ambientales han participado en los procesos de delimitación de la Ciénaga de la Virgen y su extracción y uso de recursos y servicios ambientales asociados. No obstante, dentro de los lineamientos de Adaptación al Cambio Climático para Cartagena de Indias (Invemar et al., 2012), se identificaron las problemáticas e impactos donde se reconoce al barrio El Pozón como sector vulnerable al aumento del nivel del mar, las lluvias extremas y vulnerabilidad por dengue debido a su cercanía con la Ciénaga de la Virgen.

Por su parte, el documento Plan $4 \mathrm{C}$ Cartagena de Indias Competitiva y Compatible con el Clima (Alcaldía Distrital de Cartagena de Indias et al., 2014) plantea los ejes y estrategias que la ciudad deberá implementar al año 2040 para ser una ciudad resiliente y que prevea los riesgos efecto del cambio climático. En el documento se destaca el papel que desempeñan las ONG, fundaciones y la ciudadanía en el territorio, como mecanismos de intervención y control en la ciénaga, ya que, a partir del reconocimiento de los servicios ecosistémicos importantes para las comunidades locales, se plantean respuestas para la gestión del territorio reconociendo el valor de elementos como el agua, provisión de fibras y madera, y producción de alimento, entre otros. 
Hallazgo 2. El Patrimonio Cultural Inmaterial asociado a los espacios culturales y el conflicto con la inseguridad y las barreras invisibles

La variable de Patrimonio Cultural Inmaterial asociado a los espacios culturales, a partir del reconocimiento del espacio público, barreras invisibles y servicios urbanos se registran en la cartografía como Servicios de Bienestar, donde la comunidad identifica una gran cantidad de servicios distribuidos de manera equilibrada en el territorio, siendo estos, de educación, salud, abastecimiento de alimentos (formales e informales) y equipamientos colectivos de bienestar social como los múltiples hogares comunitarios. En contraste, en la cartografía del sistema de movilidad y conectividad se pueden identificar barreras invisibles y nodos delincuenciales que, en muchos casos, coinciden con espacios deportivos.

En la figura 7 de Servicios de Bienestar es importante reconocer que, a pesar de ser uno de los barrios con mayor nivel de pobreza de la ciudad, El Pozón cuenta con siete establecimientos educativos y un sinnúmero de espacios deportivos y hogares comunitarios; también se reconoce que se prioriza el interés por atender las necesidades de la población menor de edad; y una estructura de cohesión social fuerte, que merece considerar las Barreras Invisibles y Nodos Delincuenciales, que coinciden con ciertos espacios deportivos territarias 46 20 donde se reconocen conflictos sociales en el territorio causados por pandillas (figura 8).

Algo que merece resaltar de la investigación, es encontrar que, en condiciones de asentamiento informal, se concentra un número importante de líderes sociales con metas claras, que conocen las necesidades de su comunidad, son la voz del barrio ante las entidades públicas y son quienes impulsan estrategias organizativas, las cuales han permitido mejorar la infraestructura de servicios públicos y espacios de recreación, y han propiciado el reconocimiento en la ciudad por sus actividades populares, como los grupos de danzas de ritmos caribeños y africanos, las pickup relacionadas con la champeta, la elección de la reina para el reinado popular de las Fiestas de la Independencia, las Fiestas de El Pozón que se celebran el 4 de febrero, que sin duda le dan una fuerte identidad. En contrapunto, y para la zona, la ciudad no contempla planes de mejoramiento urbano barrial; se asume la mejora de la malla vial, pero se excluye la pacificación de andenes y el mejoramiento de los espacios públicos (plazas y parques) de encuentro para la comunidad.

Se rescata el esfuerzo del Fondo de Vivienda de Interés Social y de la Reforma Urbana de Cartagena CORVIVIENDA, entidades que en los últimos años han centrado su labor en el acompañamiento social para la legalización y titularización de viviendas y el mejoramiento de las mismas. A causa de la falta de actualización 
Figura 7. Sistema de Espacio Público y Equipamiento. Servicios de Bienestar. Cartografía de síntesis construida con base en las cartografías participativas

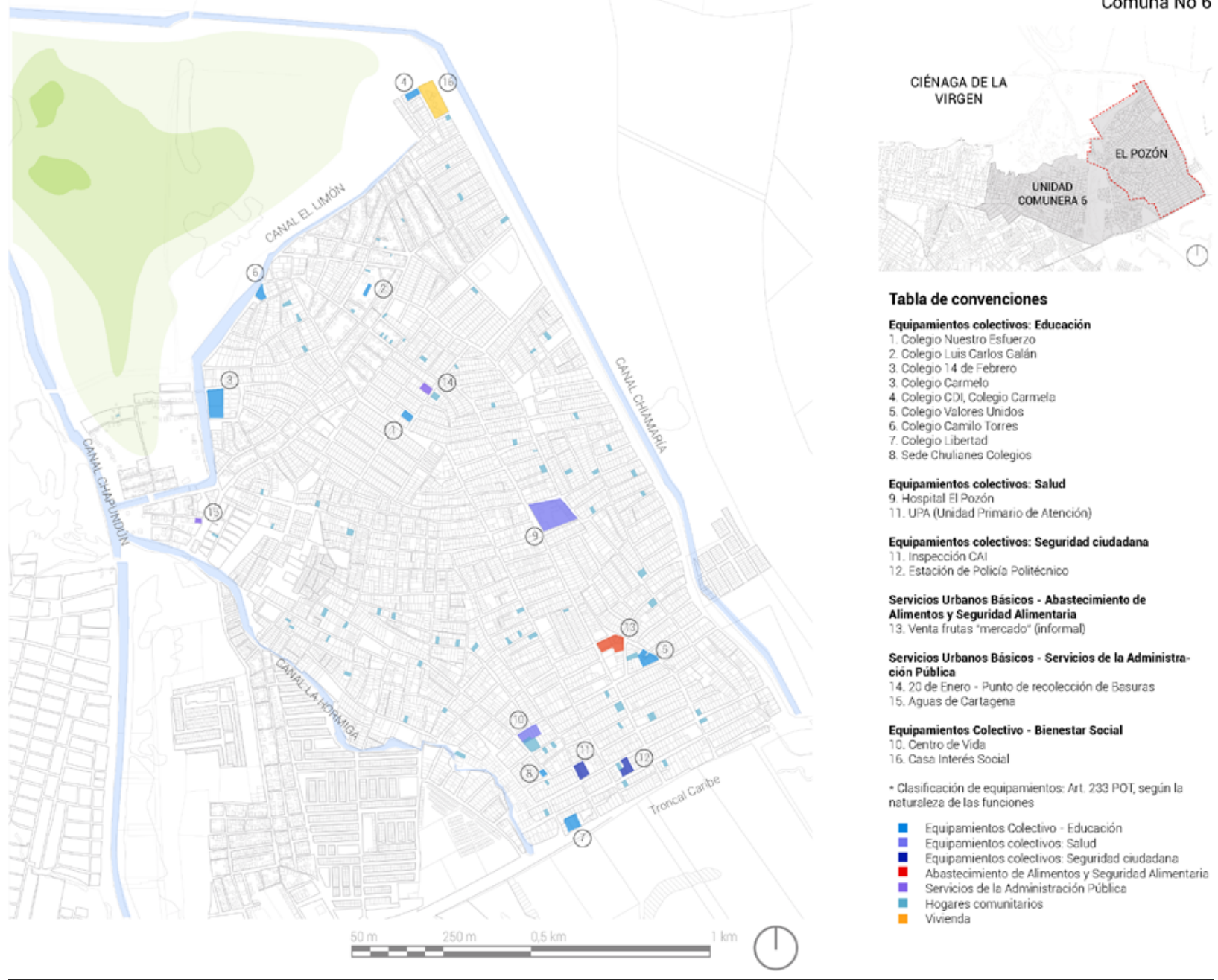

Fuente: Elaborado por Nicolás Quintero asistente de investigación UJTL. Junio, 2020.

del Plan de Ordenamiento de la ciudad (Decreto 977 de 2001), muchas de estas acciones integrales dependen de los planes nacionales y de las administraciones de los alcaldes; aquí es importante resaltar que, a nivel distrital, la falta de gobernabilidad desde el 2011 ha afectado seriamente a la ciudad en su infraestructura y a los territarias 46 
Figura 8. Barreras Invisibles: Nodos Delincuenciales.

Cartografía de síntesis construida con base en las cartografías participativas

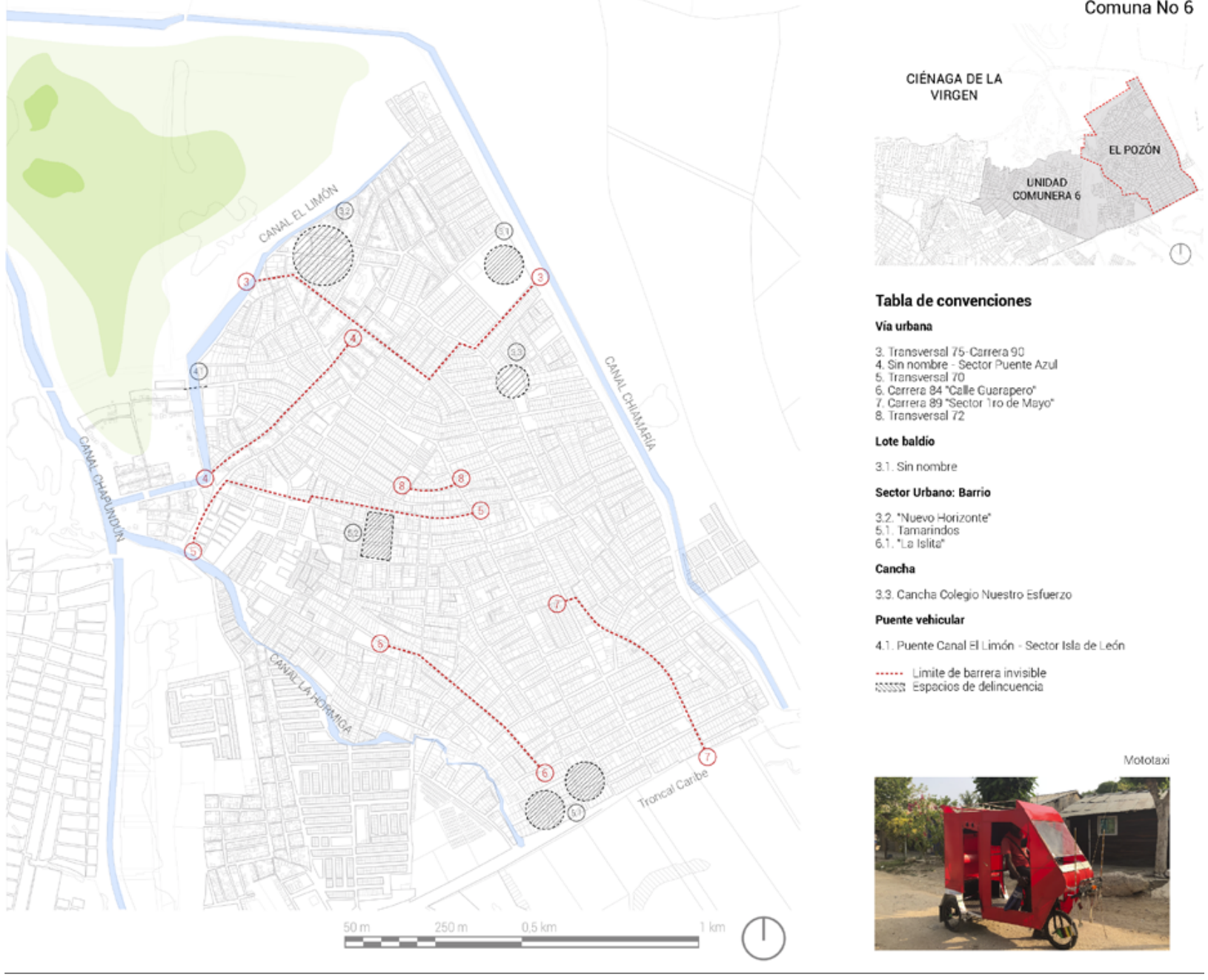

Fuente: dibujo técnico por Nicolás Quintero, asistente de investigación UJTL. Junio, 2020.

territarias 46 ciudadanos que ven perjudicada su calidad de vida. La actual administración distrital en su Plan de Desarrollo Salvemos Juntos a Cartagena, 2020-2023 (Distrito de
Cartagena de Indias, 2020), en su programa Mi Casa, Mi Entorno, Mi Hábitat, plantea realizar acciones integrales para la legalización de viviendas y barrios. 


\section{Hallazgo 3. Los Actos Festivos y Lúdicos asociados a los espacios de encuentro}

Como resultados de las Áreas Libres y Espacios Públicos (figura 9) se identificaron las terrazas relacionadas con actividades lúdico-recreativas, parques locales, elementos del sistema de equipamientos colectivos con alto valor ambiental, parques comunitarios, patios centro de manzana y antejardines. Como se mencionó en

Figura 9. Plano de Sistema de Espacio Público y Equipamiento. Áreas libres y espacios públicos. Cartografía de síntesis construida con base en las cartografías participativas
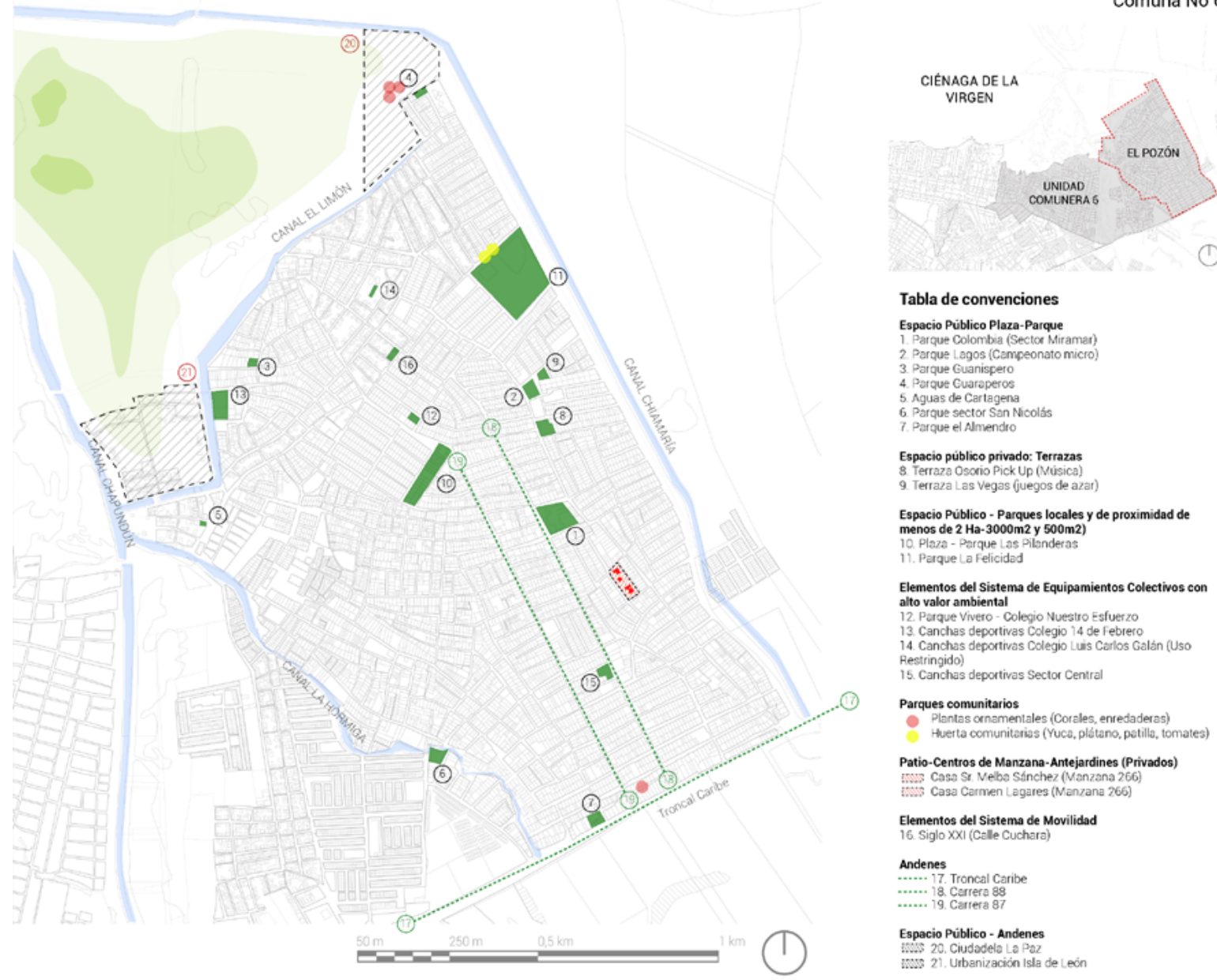

Tabla de convenciones

Espacio Público Plaza-Parque

1. Parque Colombia (Sector Miramar) 2 Parque Lagos (Cempeonato micro) 3. Parque Guanispero

5 prque Cuarapercos 6 Parque sector Son Nicoliss 7. Parque el Almendro

\section{Espacio público privado: Terrazas} Terraza oscrio Pick Up (Musica) s de azat Espacio Público - Parques locales y de proximidad de menos de $2 \mathrm{Ha}-3000 \mathrm{~m} 2$ y $500 \mathrm{~m} 2$ ) 10. Plaze - Parque Los Pilsnderas 11. Parque La Felicidad

Elementos del Sistema de Equipamientos Colectivos con alto valor ambiental

12. Parque Vivero-Colegio Nuestro Esfuerzo 14. Canchas deportivas Colegio Luis Carlos Galán (Uso Restringido) 15. Canchas deportivas Sector Central

Parques comunitarios

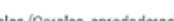
Plantas crnamentales (Corcles, enredaderas)
Huerta comunitarios (Yucs, plátano, patilla, tomates)

Patio-Centros de Manzana-Antejardines (Privados) 1.1.3. Casa St. Velba Sónchez (Manzana 266)

Elementos del Sistema de Movilidad 6 Siglo yxl (Calle Cuchara)

Andenes

..... 17. Troncal Caribe

..... 19. Cartera 8

Fuente: cartografía desarrollada por estudiantes de pregrado UJTL. Junio, 2020. 
la variable anterior, en varios de estos espacios se realizan actividades lúdicas y festivas como las presentaciones de los grupos de danza organizados por la Casa de Cultura en la Plaza-Parque de Las Pilanderas o el reinado popular, que se realizaba en el Colegio 14 de febrero.

Los equipamientos relacionados con la educación y el bienestar social son espacios de vital importancia para la comunidad, son el centro de su vida comunitaria a pesar de tener condiciones complejas, su espacio público ha sido producido y auto gestionado por la comunidad, como parte de su proceso de asentamiento informal como se puede observar en la figura 10.

\section{Conclusiones y recomendaciones finales}

Los criterios de valoración del Patrimonio Cultural material e inmaterial se tornan la base de la discusión, normativamente, la UNESCO es clara en establecer los criterios de evaluación de "Valor Excepcional Universal" relacionados con poseer una importancia cultural que trasciende las fronteras nacionales $(1972$, p. 48). Y a nivel nacional, la Ley General de Cultura atribuye tres valores a los Bienes de Interés Cultural: el valor histórico, el valor estético y el valor simbólico. Este último está muy relacionado con las manifestaciones de Patrimonio Cultural Inmaterial, sin embargo, cuando hablamos de maniterritarias 46 festaciones contemporáneas, que suceden en espacios marginales con condiciones físicas, económicas y sociales complejas, se peca al pensar que no es posible encontrar elementos de valor, así sean estos otorgados por las personas y comunidades que los disfrutan, evocan o contemplan.

Por esto, en el barrio El Pozón, con la aplicación de herramientas participativas, fue posible identificar que, a pesar de no cumplir completamente con los criterios establecidos por la normativa cultural como comunidad, tienen claro cuáles son las actividades que, por ser elementos de tradición, consolidan la identidad Pozonera que antepone el derecho colectivo al sistema de valoración técnico.

En perspectiva al escenario social, político y cultural de la contemporaneidad, la política cultural debería propender por fortalecer la identidad cultural integrando a los diferentes actores alrededor de la misma, fortaleciendo los tejidos sociales que cada vez se encuentran más en riesgo. Las personas que se apropian de manifestaciones o espacios culturales generalmente no los separan entre materiales o inmateriales simplemente los viven, por lo cual es deseable que desde el punto de vista normativo los criterios de valoración sean reconsiderados.

De aquí deriva la importancia de realizar inventarios de patrimonio cultural participativos; en contextos urbanos tan dinámicos y cambiantes existe el riesgo de perder esos elementos identitarios y de cohesión social. En América Latina existen 
Figura 10. Plan de Sistema de Espacio Público y Equipamiento. Espacios de Encuentro.

Cartografía de síntesis construida con base en las cartografías participativas

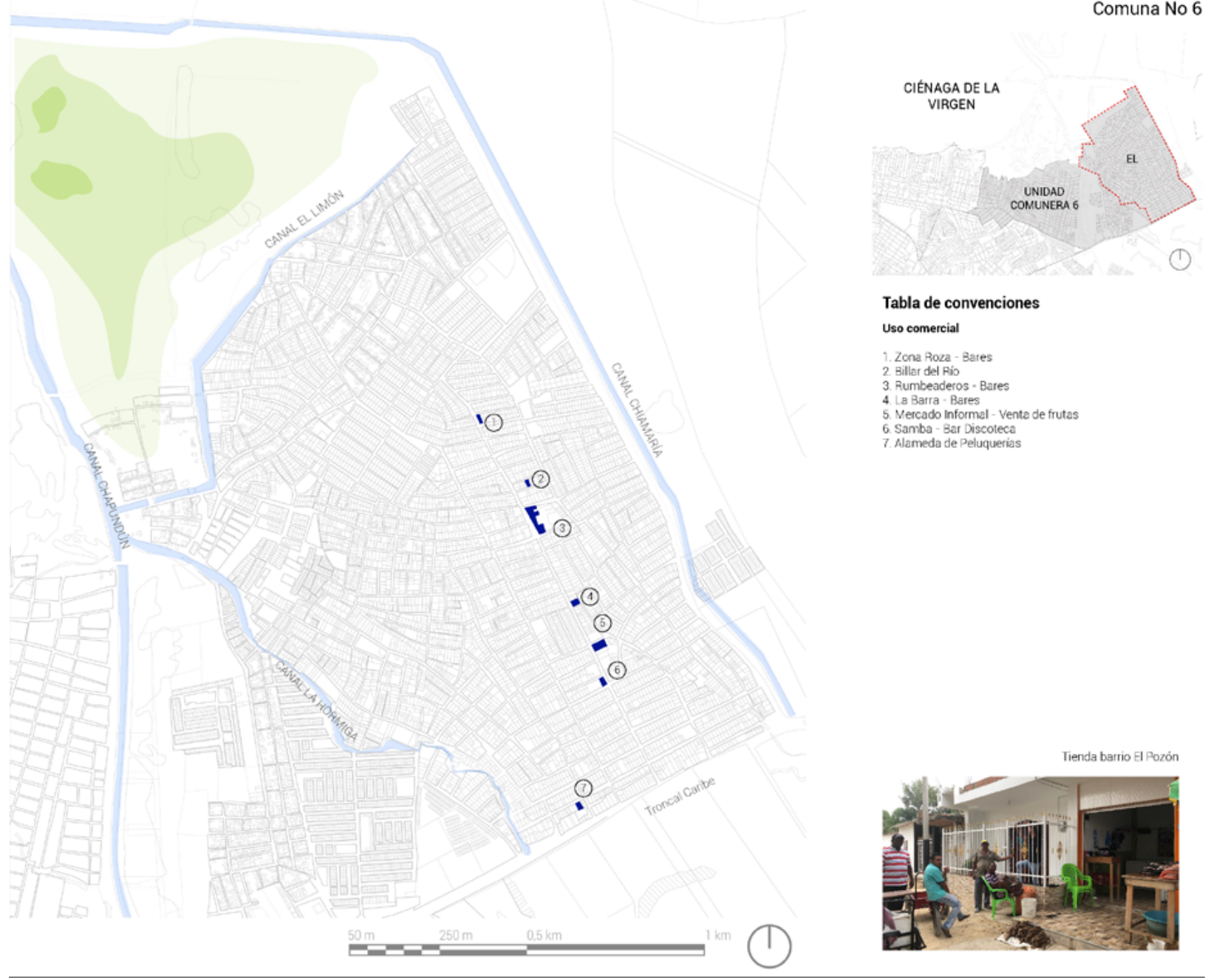

Fuente: dibujo técnico por Nicolás Quintero, asistente de investigación UJTL. Junio, 2020.

manifestaciones que hacen parte de la identidad cultural de los contextos urbanos que, por no cumplir con los criterios normativos, no han sido inventariados y han desaparecido; o por encontrarse en áreas marginales que, como se expuso en 
la hipótesis, muchas veces se piensa que por las características de sus servicios urbanos y sus estructuras sociales no es posible considerar que no es viable encontrar valores culturales. El Pozón, sin embargo, hizo posible reconocer que las herramientas participativas son potentes para apoyar a este tipo de comunidades a valorar aún más aquellas actividades y lugares que hacen parte de su vida cotidiana, y para visibilizarlos ante las otras comunidades residentes en la ciudad y promover el derecho a la ciudad.

\section{Referencias}

Alcaldía de Cartagena de Indias, MADS, INVEMAR, CDKN; Cámara de Comercio de Cartagena. (2014). A. P. Zamora, A. López, V. Trujillo, C. Martínez, G. Llinás, \& M. Lacoste (Eds.), Plan 4c. Cartagena de Indias competitiva y compatible con el clima [Serie de publicaciones generales del INVEMAR N. ${ }^{\circ}$ 63]. https://www.minambiente. gov.co/images/cambioclimatico/pdf/ nodo_caribe/Plan_4_C_Cartagena_ Competitiva_y_Compatible_con_el_ Clima.pdf

Arteaga, I. (2005, enero-diciembre). De la periferia a la ciudad consolidada. Estrategias para la transformación de zonas urbanas marginales. Bitácora urbano Territorial, 9(1), 98-111. https://revistas.unal.edu.co/index.

\section{tersitarias 46}

Cerasi, M. (1973). Citta i periferia: condizioni e tipi della residenzia delle classi subalterne della citta moderna. Cooperativa libraria universitaria del Politecnico.

Choay, F. (1976). Urbanismo: Utopias y realidades. Lumen.

Cingolani, P. (2009). Marginalidad(es). Esbozo de diálogo Europa-América Latina acerca de una categoría sociológica. Revista Latinoamericana de Estudios del Trabajo, 14(22), 157-166. https://dialnet.unirioja.es/servlet/ articulo? codigo $=3223123$

Decreto 0977 de 2001. Por medio del cual se adopta el Plan de Ordenamiento Territorial del Distrito Turístico y Cultural de Cartagena de Indias. https:// vuc.cartagena.gov.co/documentos/ normatividad/DECRETO_0977_ de_2001.pdf

Delfino, A. (2012, julio-diciembre). La noción de marginalidad en la teoría social latinoamericana: surgimiento y actualidad. Universitas Humanistica, (74), 17-34. http://www.scielo.org. $\mathrm{co} / \mathrm{pdf} / \mathrm{unih} / \mathrm{n} 74 / \mathrm{n} 74 \mathrm{a} 02 . \mathrm{pdf}$

Distrito de Cartagena de Indias. (2020). $A B C$ del Plan de Desarrollo Salvemos Juntos a Cartagena 2020 / 2023. https://www.cartagena.gov.co/Documentos/2020/Transparencia/ TyALaIP/Planeacion/PlanesDeDesarrollo/2020-2023/PD310720/ A BC\%20Plan\%20de\%20Desarrollo\%202020.pdf 
Econometría Consultores. (2014). Linea Base de la Intervención de la Fundación Social en Cartagena [ID 100632, Fundación Social]. https:// portal.econometria.com.co/es/ proyectos? buscar $=$ fundacion $\% 20$ social Fracasso, L., \& Mesa, S. (2019). Valorar lo patrimoniable: hábitat popular y patrimonio cultural. Designia, 6(2), 85-115. https://doi. org/10.24267/22564004.402

IAvH. (2016). Propuesta de límite del humedal en la ventana piloto ciénaga de la virgen [Ventana de Estudio, Convenio 13-014 (FA.0005 de 2013)]. http://repository.humboldt.org.co/bitstream/ handle/20.500.11761/9526/Propuesta $\% 20$ de $\% 201 \%$ C3\%ADmite $\% 20$ de $\% 201$ a $\% 20 \mathrm{Ci} \% \mathrm{C} 3 \%$ A 9 naga $\% 20$ d e $\% 20 \mathrm{~L} \mathrm{a} \% 20 \mathrm{~V}$ irge n $\% 20$ $\% 28$ Cartagena $\% 2$ C $\% 20$ Bolivar $\% 29$. pdf? sequence $=1$ \&isAllowed $=y$

INVEMAR; MADS; Alcaldía Mayor de Cartagena de Indias; CDKN. (2012). G. X. Rojas, J. Blanco, \& F. Navarrete (Eds.), Lineamientos para la adaptación al cambio climático de Cartagena de Indias. Proyecto Integración de la Adaptación al Cambio Climático en la Planificación Territorial y Gestión Sectorial de Cartagena de Indias [Serie de publicaciones generales del INVEMAR N. $\left.{ }^{\circ} 55\right]$. https://cdkn.org/ wp-content/uploads $/ 2012 / 08 / \mathrm{Li}^{-}$ neamientos-de-Adaptaci\%C3\%B3nal-CC-Cartagena.pdf
Johnson, R. B. (1997). Examining the validity structure of qualitative research. Education, 118(2), 282-292.

Lacol, Cooperativa de Arquitectos. (2018). Construir en colectivo. Participación en arquitectura y urbanismo ( $\mathrm{l}^{\mathrm{a}} \mathrm{ed}$.). Pol-len.

Lanzafame, F., \& Quartesan, A. (Eds.) (2009). Pobreza en áreas Centrales Urbana. Métodos de análisis e intervenciones: Manual de consulta para profesionales. BID. https://issuu. com/idb_publications/docs/book_ es_3258/44

Ley 1037 de 2006. Por medio de la cual se aprueba la "Convención para la Salvaguardia del Patrimonio Cultural Inmaterial", aprobada por la Conferencia General de la Unesco en su XXXII reunión, celebrada en París y clausurada el diecisiete (17) de octubre de dos mil tres (2003), y hecha y firmada en París el tres (3) de noviembre de dos mil tres (2003). Diario Oficial N. ${ }^{\circ} 46.741$ de 4 de septiembre de 2007. http://www. secretariasenado.gov.co/senado/basedoc/ley_1037_2006.html

Ley 1185 de 2008. por la cual se modifica y adiciona la Ley 397 de 1997 (Ley General de Cultura) y se dictan otras disposiciones. Diario Oficial N. ${ }^{\circ} 46.929$ de 12 de marzo de 2008. http://www.secretariasenado.gov.co/ senado/basedoc/ley_1185_2008.ht$\mathrm{ml}$

Llop, J. M., Valls, X., Albors, J., \& Mongil, D. (2008). Ciudades en territarias 46 
Reconstrucción. ¿Hacia una nueva cultura urbanística? En Ciudades en (re)construcción: necesidades sociales, transformación y mejora de barrios (pp. 13-27) [Colección Estudios, Serie Territorio 5]. Diputació de Barcelona. http://www.unizar.es/carmeng/documents/CiudadesenReconstruccion. pdf

Marradi, A, Archenti, N, \& Piovani, J. (2018). Manual de metodología de las ciencias sociales ( $\mathrm{I}^{\mathrm{a}}$ ed.). Siglo XXI.

MinCultura. (2010). P-Patrimonio cultural para todos: una guia de fácil comprensión. Imprenta Nacional.

MinCultura. (201la). Guías para el conocimiento y la gestión del patrimonio cultural inmaterial. Módulo I: conceptos. http://patrimonio.mincultura. gov.co/Documents/G-Conceptos.pdf

MinCultura. (2011b). Convención y Politica de Salvaguardia del PCI. https:// www.mincultura.gov.co/areas/patrimonio/publicaciones/Documents/ C-Convenci $\%$ C 3 \% B 3n \% 20 y $\% 20$ pol\%C3\%ADtica\%20de\%20salvaguarda\%20del\%20PCI.pdf

Naciones Unidas. (2018). Agenda 2030 y los Objetivos de Desarrollo Sostenible. Una oportunidad para América Latina y el Caribe. https:// repositorio.cepal.org/bitstream/ handle/11362/40155/24/ S1801141_es.pdf
Niglio, O. (2014). Inheritance and Identity of Cultural Heritage. Advances in Literary Study, (2), 1-4. Doi: 10.4236/ als.2014.21001.

Paisaje Transversal. (2019). Escuchar y transformar la ciudad. Urbanismo colaborativo y participación ciudadana. Los libros de Catarata.

PNUMA, Alcaldía de Cartagena de Indias, EPA, Observatorio del Caribe. (2009). Perspectivas del Medio Ambiente Urbano: GEO Cartagena. http://observatorio.epacartagena.gov.co/ wp-content/uploads/2016/06/geocartagena.pdf

Salgado Lévano, A. C. (2007). Investigación cualitativa: diseños, evaluación del rigor metodológico y retos. Liberabit, 13(13), 71-78. http://www.scielo.org.pe/scielo. php? script $=$ sci_arttext\&pid $=$ S1729$48272007000100009 \& \operatorname{lng}=$ es \&tln $\mathrm{g}=\mathrm{es}$

Salvia, A. (2010). De marginalidades sociales en transición a marginalidades económicas. En N. Cohen, \& C. Barba (Coords.), Los desafios de la cohesión social en América Latina (pp. 107135). CLACSO.

Sandín Esteban, M. P. (2000). Criterios de Validez de la investigación cualitativa: de la objetividad a la solidaridad. Revista de Investigación Educativa, 18(1), 223-242. https://revistas. um.es/rie/article/view/121561 
UNESCO. (1972). Convención sobre la protección del patrimonio mundial, cultural y natural. http://whc.unesco.org/ archive/convention-es.pdf

UNESCO. (2003). Convención para la salvaguardia del patrimonio cultural inmaterial. http://portal.unesco.org/
es/ev.php-URL_ID =17716\&URL_ $\mathrm{DO}=\mathrm{DO} \_\mathrm{TOPIC} \& \mathrm{URL} \mathrm{L}_{-} \mathrm{SEC}-$ TION $=201 . h t m l$

Wacquant, L. (2001) Parias urbanos. Marginalidad en la ciudad a comienzos del milenio. Manantial. 